\title{
On the Construction of WeChat-based Platform of Great Courses
}

\author{
Lieming Fang ${ }^{1, ~ a}$ and Min Zhang ${ }^{1, b^{*}}$ \\ ${ }^{1}$ Shandong Youth University of Political Science, Jinan, China \\ afanglieming@126.com, b1491197554@qq.com
}

\section{Keywords: WeChat platform; Great courses; Courses construction}

\begin{abstract}
MOOC and Microteaching, just like "a digital tsunami", are sweeping the entire education circle. Scholars have different opinions and each of them sticks to his or her argument. By comparing the Great Courses based on WeChat platform, MOOC, and micro teaching, the authors propose the construction principles of the Great Courses on the campus WeChat platform, that is, upload the existing resources of the Great Courses to the WeChat platform. In this way, the advantages of intelligent mobile devices under the network background are combined with the traditional teaching mode to improve the quality of teaching.
\end{abstract}

\section{Introduction}

In recent years, with the rapid development of the Internet technology and smart mobile devices (such as smart mobile phone, tablet computer) the high-tech equipment based on the Internet technology and smart, mobile, real-time interactive software is rapidly changing people's lifestyles and habits. WeChat is important software based on smart mobile devices with a huge number of users, especially college students. The present Great Courses in China are best of the best courses with first-class teachers, first-class teaching contents, first-class teaching methods, first-class teaching materials and first-class teaching management which play a model role in courses construction. On campus, the existing courses related to the content are uploaded to the WeChat public platform which is featured by interactive and sharing function. Students can make full use of time confetti to learn, teachers and students can interact and discuss; teachers can solve students' doubts and check students' homework at any time. In this way, they can make full use of high-quality curriculum resources in the Great Courses and achieve better effects.

\section{A Brief Introduction to Wechat- based Platform of Great Courses on Campus}

The WeChat-based Great Courses platform is an improved construction of the existing Great Courses. It makes full use top-quality curriculum resources by uploading the materials including syllabus to the WeChat platform. That is to say, the traditional teaching is transformed to WeChat platform-based teaching where the instant teaching and learning could be realized. Students can learn at any time and there is more interaction between teachers and students.

WeChat Based Platform of Great Courses takes advantage of network teaching with all content of the courses transferred to the WeChat public platform. As the capacity of some video files is large, a link could be created to reach the website of Great Courses database. With a click away, the users can get access to the online video teaching.

Through the interactive network windows in the platform, a lot of functions could be realized: real time interaction between teachers and students, voice communication between teachers and students, students' feedback, teachers' online question- answering and homework correcting and so on. In this way, the existing Great Courses construction could be improved. The current increasingly widespread used smart phones, tablet computers are sound media for WeChat platform.

\section{Comparison Among WeChat-based Great Courses Platform, MOOC, and Micro Teaching}

WeChat based Great Courses Platform combines the advantages of the Courses and WeChat public platform. WeChat platform enjoys the advantages of real-time, interactive. Thus, the high quality of 
teaching could be realized.

Generally speaking, the WeChat- based Great Courses Platform has the following characteristics:

1. Adiversified curriculum resource are available. On WeChat public platform, multi courses are available instead of only one.

2. It is easy to use. Smart phones in the colleges and universities have been widely used, and mobile applications, wireless network are gradually covering the campus, which have laid the sound foundation for public platform. Teachers and students in colleges and universities are intellectuals, the main WeChat users and also the main information consumer groups. Widespread use of WeChat, as well as its convenient operation, making micro channel based on platform of course easy to use. Students can turn on their mobile phones to study at anytime, anywhere.

3. It has a wide range of learners. To learn on a WeChat- based Great Course, users could enter it by scanning two-dimensional code, be they students in college or in other college or even from other universities. What they need do is to search for the WeChat name and scan. Therefore, it has a wide range of learners.

4. It can inspire students' motivation to learn. In the WeChat-based Great Courses platform, students can learn in their brief scraps of leisure time, on a bus, subway and in other shorter idle time. Thanks to the convenience and efficiency of the platform, it is easier to inspire students' learning motivation and enhance students' autonomous participation.

5. It has interactive function like MOOC. Through binding account and student ID, students can easily complete the homework assigned by the teacher, and in the process to finish the homework they can have real time interaction with teachers and other students. What's more, by controlling the Client teachers can get informed of the students' work and adjust teaching strategies when needed.

6. The courses are free to learn. On the WeChat based Great Courses learning platform, teachers and students only need to follow the public number of the platform to learn. There is no need to buy the courses. Therefore, it saves money and it is a blessing for the students who are financially disadvantaged.

MOOC is popular in the world for it has following advantages:

1. It's easy to use. All MOOC learners need are internet and the longing for knowledge. If time permitted, just register and you can study at once.

2. Famous schools and teachers are available. MOOC's teaching model is connected to the world. Learners can learn a MOOC once they register a learning account following MOOC's requirements. They can learn top-quality courses under the guidance of famous teachers and professors.

3. It has wide coverage. No matter what rank and position learners are, all of them can get teachers' guidance by MOOC.

4. MOOC is rich in resources. MOOC's resources cover almost all school and teachers' courses. Learning resources is really abundant.

Meanwhile, during the application it also has some problems.

1. Courses' construction and requirements are too complicated. If college teachers open a MOOC, it's necessary for teachers to get trained to meet the requirement which is a big challenge for the teachers.

2. Inconvenience and ineffectiveness of management for teachers. Once a MOOC course is on line, the amount of registered students is likely to reach "million", which puts a new challenge to management. Should the registered students in other universities need to be managed differently with that in the university? And how to manage it? How to give evaluation? How to give credit? Should the existing policies applicable to the MOOC students? If it should be revised, what will be done? All the questions deserve the concern of the management authorities of universities.

3. Most of courses are taught in English. Nowadays students tend to use the platform at home while most of MOOC is designed for western countries. Most of top-class courses are set in English language and English takes most part of MOOC, so it leads to students' inconvenience when learning.

4. The number of free courses on MOOC is limited. In many MOOC courses, the front part is free while the following parts are not free for some on-line courses. The cost discourages students' 
enthusiasm to learn.

5. Learners' learning persistence is poor. In the end of the year 2013, Graduate School of the University of Pennsylvania conducted a survey on MOOC course finishing rate on Coursera. The survey included 16 courses such as science, literature and other engineering courses and covered 100 Million registered users on Coursera, which shows that only $4 \%$ of students finish the courses completely.

6. There is high dropout rate. Many students choose MOOC because of 3-minute passion. If they lost interests or owing to other subjective reasons, they drop out. And that is a serious problem in MOOC's teaching.

7. The interaction is not enough. Compared with the traditional class, learning on MOOC makes it difficult for students and teachers have interaction immediately since there is hysteresis online. It also discourages students' interests in learning.

8. It fails to meet the requirements of Practice teaching. Anyway, MOOC is just an assisted instruction. It can't replace the face- to- face teaching model which is more lively, relevant and better planned.

9. Credit certification on MOOC has been questioned. At present, some colleges accept the credit while some others deny it. What's more, they refuse to admit the degree got on MOOC.

Micro class has the following advantages:

1. The lesson design is simple and the goal is clear. Due to the short duration of the micro(only 5 to 6 minutes),the students can enter studying state quickly. They can't easily feel tired and would be ready to pay attention to the class.

2. It saves the time to study and research. Compared with the traditional online courses, the micro class has short teaching time; what's more, the capacity of the micro video is smaller, which is convenient to watch at any time.

3. There is no strict restriction of time and space. The Micro class' video resource is abundant, and it has a large amount of information, so that learners can watch and study it again and again without the time and space restriction.

But Micro class also has some disadvantage:

1. Insufficient teaching time;

2. Less teaching content;

3. Relatively small resource capacity.

\section{Construction of WeChat-based Platform of Great Courses}

1. Construct campus WeChat platform.

Firstly, the campus WeChat public platform should be erected. The account can be named after the university-level Great Course, school-level Great Course or one certain Great Course. Then Interlinkage can be created to connect every Great Course.

2. Upload the main content of Great Course (such as the syllabus, courseware, etc) to WeChat platform.

The construction of the excellent course's WeChat platform mainly includes uploading the Great Course's syllabus, teaching courseware, tests, related pictures, and related video to the WeChat public platform. Then make the WeChat official account known to students. In this way, they can experience and learn the courses on WeChat platform. Feedback could be collected from students and the platform be improved constantly.

3. How to insert video in WeChat platform-based Great Course

The files in WeChat platform are small while the video of Great Course is too large. Therefore, a link can be connected directly to the videos on the website of Great Courses, or put the video to the YunFile, set link and then learners can watch the video by clicking on the link of the video. Thus, the problems of small capacity of WeChat platform and non-smooth video operation could be solved.

4. Design interaction links of WeChat. 
Due to function of online communication and social contact function of WeChat, communication exchange of "one to many" mode could be realized. Interactive zone on WeChat platform can be set to achieve the interaction between teachers and students. Students can talk directly with teachers and their peers, teachers can explain the questions and check homework.

5. Create the new model of "Online teaching" and "On line lessons preparation"

On WeChat platform, teachers can prepare lessons, write syllabus, discuss about curriculum issues, and share new ideas and new methods. When the traditional curriculum is put on the WeChat platform, the teaching and research work will be more efficient.

\section{Conclusion}

MOOC has been sweeping through the whole education circle like "a digital tsunami". Scholars' attitude towards MOOC divided. We can't be blindly optimistic about MOOC for its advantages in theory. Due attention should be drawn to the problems of MOOC, such as lack of persistence of learning, high dropout rates, lack of interaction, difficult to meet the need of practice teaching, single teaching mode, credit certification failing to get admission and so on. The micro teaching's content is less, the time of duration is short and there is relatively less resource capacity. We boldly propose put existing Great Courses resources on campus WeChat platform, thus by combining the traditional teaching mode with high technology, the high quality of teaching could be achieved.

\section{Acknowledgements}

The paper is funded by the following projects: 2013 Shandong Province-level University Great Course---"Labor Economics" (course No. 2013 BK386); 2015 Training Plan to Innovation and Enterprise of National University Students (No. 201514277008)

\section{References}

[1] Shan Feng, Tan Xiaohong, Xue. Mobile Learning Based on the WeChat Platform: An Empirical Study Data Structure [J].Open Education. 2015 (2) Vol.21, No. 1.

[2] Liao Xiaoming. Analysis of the Social Effect and the Blocking Mechanism of Great Courses Resources Sharing in the University [J]. Journal of Southwest Agricultural University: Social Science Edition, 2011 (5):25.

[3] Shuiming. Using the WeChat Teaching Platform to Improve Interaction -- A Case Study of Zhejiang Sci-Tech University [J]. Journal of Higher Education, 2015 No.19 8---13.

[4] Shen Yang. On the WeChat-based mobile learning platform [J]. Journal of Xiamen City University, 2015 (9) Vol.17 No. 3.

[5] Sheng Weifang. On the Operation Strategy of WeChat Campus Public Platform [J]. Jiannan Literature, 2013, 02: 318-319.

[6] He Yunliang, Zhang Guiyun, CaiDekun. Application of WeChat Public Platform in Universities [J]. Journal of Qujing Normal University, 2014, 03: 60-62.

[7] Li Jing. On the Challenges MOOCS bring to Universities and Coping Strategies [J]. Changchun Education Institute Journal, 2015 (9) Vol. 31 No. 18. 